\title{
Towards a long-term homogenized UTH data set derived from satellite microwave measurements
}

\author{
V. O. John ${ }^{a}$, S. A. Buehler ${ }^{b}$, M. Kuvatov ${ }^{c}$, B. J. Soden ${ }^{a}$, and T. R. Sreerekha ${ }^{d}$ \\ ${ }^{a}$ Rosenstiel Scool of Marine and Atmospheric Science, University of Miami, Miami, USA; \\ ${ }^{b}$ Lulea Technical University, Department of Space Science, Kiruna, Sweden; \\ ${ }^{c}$ IUP, University of Bremen, Germany; \\ ${ }^{d}$ Satellite Applications, Met Office, Exeter, UK
}

\begin{abstract}
This article presents some ideas and issues related to the creation of a long-term upper tropospheric humidity (UTH) data set using satellite based microwave measurements. Polar orbiting satellites have been measuring UTH for more than a decade now. There are three microwave instruments which can measure UTH from Space: Special Sensor Microwave/Temperature-2 (SSM/T2), Advanced Microwave Sounding Unit-B (AMSU-B), and Microwave Humidity Sounder (MHS). These instruments have channels at $183.31 \pm 1.00 \mathrm{GHz}$ which are sensitive to UTH. Retrieval of UTH and cloud issues are discussed in detail. Advantage of microwave measurements of UTH over infrared measurements are demonstrated. Preliminary results on the inter-calibration of these instruments are also shown.
\end{abstract}

Keywords: microwave, upper tropospheric humidity, inter-calibration

\section{INTRODUCTION}

It has been widely recognized that the increase in water vapor associated with an increase in anthropogenic greenhouse gases, such as $\mathrm{CO}_{2}$, provides the largest positive feedback to the greenhouse warming of the Earth and its atmosphere. ${ }^{1}$ Although there is a considerable spread in the water vapor feedback values, Global Climate Models (GCMs) simulate a water vapor feedback which follows an increase in water vapor conserving relative humidity. ${ }^{2}$ This spread in water vapor feedback values can, to a certain extend, be explained by the uncertainty in the simulation of UTH by these models.

Water vapor in the lower troposphere is mainly thermodynamically controlled so that its representation in the models is good enough, but the water vapor in the upper troposphere, which has more impact on the outgoing longwave radiation due to colder temperatures in the upper troposphere, is controlled not only by thermodynamics but also by large scale dynamics and to a lesser extend by cloud micro-physics. Reproducing realistic upper tropospheric humidity $(\mathrm{UTH})$ values warrants correct simulation of water feedback values by the models. Thus, it is important to monitor long term changes in UTH to better understand and predict climate change. Several studies have expressed demand for a good quality, long-term upper tropospheric water vapor data set to better understand water vapor feedback. ${ }^{3}$

Satellite measurements of UTH make this long-term monitoring of UTH possible in a global sense. A channel at $6.7 \mu \mathrm{m}$ (Channel 12) of High Resolution Infrared Radiation Sounder (HIRS) had been measuring UTH since 1979. This data set has been extensively used to study UTH and its impact on climate. Unfortunately, from 1998 onwards the spectral characteristics of this channel has been changed. The nominal wavelength of this channel has been changed from $6.7 \mu \mathrm{m}$ to $6.5 \mu \mathrm{m}$. This has caused a brightness temperature difference of about $7 \mathrm{~K}$ between HIRS/2 (prior to 1998, till NOAA-14) and HIRS/3 (NOAA-15, 16, and 17). This is illustrated in Figure 1, which shows the difference between HIRS/2 on NOAA-14 and HIRS/3 on NOAA-15 for a diverse set of 42 profiles (for details on the profiles see Garand et al. $\left.(2001)^{4}\right)$. The brightness temperatures are calculated

Further author information: (Send correspondence to V. O. John)

V. O. John: E-mail: vojohn@rsmas.miami.edu, Telephone: 13054214011

Microwave Remote Sensing of the Atmosphere and Environment V, edited by Azita Valinia, Seiho Uratsuka,

Tapan Misra, Proc. of SPIE Vol. 6410, 64100K, (2006) · 0277-786X/06/\$15 · doi: 10.1117/12.694305 


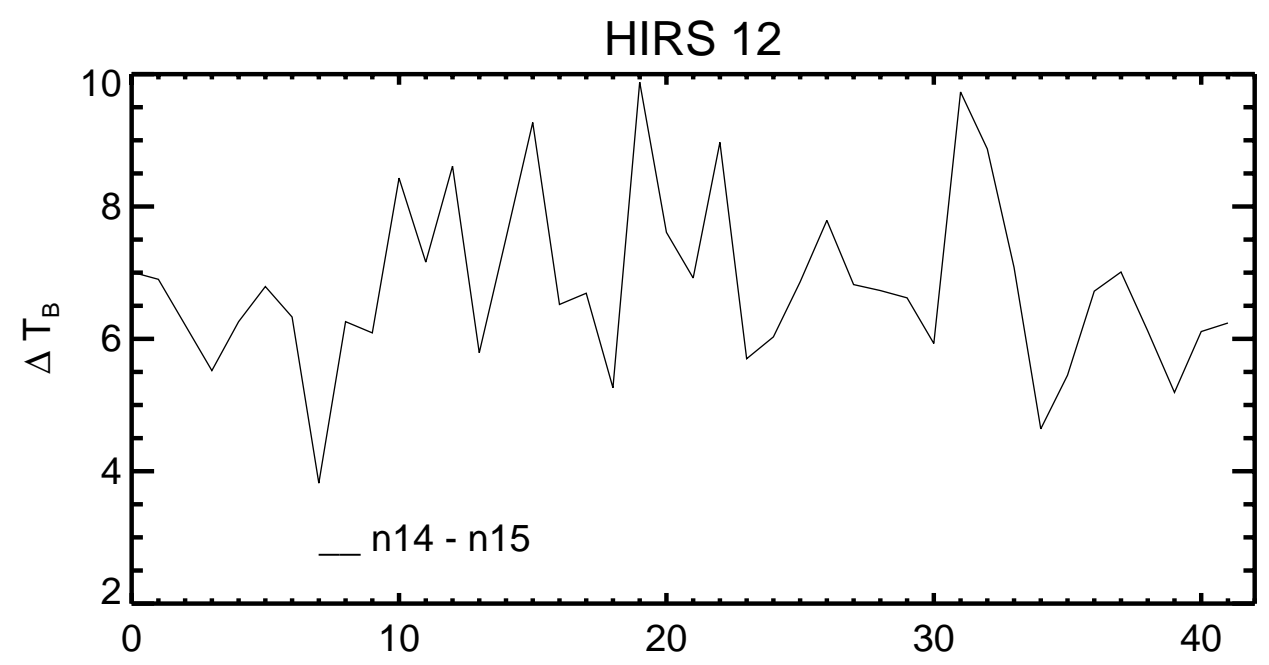

Figure 1. Difference in HIRS Channel 12 brightness temperature for HIRS/2 on NOAA-14 and HIRS/3 on NOAA-15. These are simulations using RTTOV for a diverse set of 42 profiles.

using the radiative transfer model RTTOV. This introduces a discontinuity in the measurements of UTH by HIRS instruments.

A drawback with infrared measurements of UTH around $6.7 \mu \mathrm{m}$ is contamination by clouds. The data cannot be used in presence of any clouds in the upper troposphere. This leads to a clear-sky bias in UTH data set derived from these measurements which is about $10 \% .^{5}$ The issue of clouds will be discussed in more detail in Section 3.1.

Another source of continuous upper tropospheric humidity data is satellite microwave measurements. A channel at $183.31 \pm 1.00 \mathrm{GHz}$ has been measuring UTH since 1994 . There are mainly three microwave radiometers which can measure UTH. They are: SSM/T2 on Defense Meteorological Satellites Program (DMSP) satellites, AMSU-B on NOAA-15, 16, and 17 satellites and MHS on NOAA-18 and MetOp-1 satellites. These instruments are cross-track scanning, passive, total power radiometers which measure thermal radiation emitted by the Earth's surface and atmosphere. Time span of data from different instruments are presented in Table 2 . It should be noted that the spectral characteristics of the channel sensitive to upper tropospheric humidity is very similar for the three instruments. Therefore one can expect the radiances measured by these instruments to be similar. Thus, this provides a unique opportunity to make a long-term homogeneous UTH data set.

Moreover, microwave measurements are less affected by clouds compared to infrared measurements. It has been shown that only precipitating clouds affect microwave UTH measurements. ${ }^{6}$ Therefore UTH data set derived from these measurements will not contain significant clear-sky bias.

The article is organized as follows: Section 2 describes the microwave instruments and data, Section 3 summarizes retrieval of UTH from $183.31 \pm 1.00 \mathrm{GHz}$ brightness temperatures $\left(T_{\mathrm{B}}^{ \pm 1}\right)$, and cloud and surface issues, Section 4 presents some results on inter-calibration of these instruments.

\section{MICROWAVE INSTRUMENTS}

\subsection{SSM/T2}

The SSM/T2 is a cross-track scanning, five channel, passive total power microwave radiometer system which consists of a single, self-contained module with a step-scan motion in the cross-track direction of \pm 40.5 degrees. The SSM/T2 observation rate is 7.5 scans per minute. There are 28 observations (beam positions) per scan for each of the five channels, with each observation having a spatial resolution of approximately $48 \mathrm{~km}$. All five channels have coincident centers. The total swath width for the SSM/T-2 is approximately $1500 \mathrm{~km}$ (See Table 1 for details). 
The five channels of SSM/T2 are designed to measure atmospheric humidity. The three channels centered around a strong water vapor line at $183.31 \mathrm{GHz}$ measure humidity at three different layers of the atmosphere. The channel which is closest to the line center, located at $183.31 \pm 1.00 \mathrm{GHz}$, measures the upper tropospheric humidity.

Data from SSM/T2 are available from June 1994 to present from the Comprehensive Large Array-data Stewardship System (CLASS) of National Atmospheric and Oceanic Administration (NOAA). See Table 2 for details.

Table 1. Channel characteristics of the instruments. $f_{C}$ is the central frequency of the channel, $\Delta \mathrm{f}$ is the passband width, $\mathrm{NE} \Delta \mathrm{T}$ is the noise equivalent temperature, and $\mathrm{S}$ is the swath width.

\begin{tabular}{|c|c|c|c|c|c|c|}
\hline Ch. & $\begin{array}{c}\mathrm{f}_{C} \\
{[\mathrm{GHz}]}\end{array}$ & $\begin{array}{c}\Delta \mathrm{f} \\
{[\mathrm{GHz}]}\end{array}$ & No. of Pass Bands & $\begin{array}{c}\mathrm{NE} \Delta \mathrm{T} \\
{[\mathrm{K}]}\end{array}$ & $\begin{array}{c}\text { Beam Width } \\
\text { [deg] }\end{array}$ & $\begin{array}{c}\mathrm{S} \\
{[\mathrm{km}]}\end{array}$ \\
\hline \multicolumn{7}{|c|}{$\overline{\mathrm{SSM} / \mathrm{T} 2}$} \\
\hline 2 & $183.31 \pm 1.00$ & 0.5 & 2 & 0.80 & 3.0 & 1500 \\
\hline 1 & $183.31 \pm 3.00$ & 1.0 & 2 & 0.60 & 3.0 & 1500 \\
\hline 3 & $183.31 \pm 7.00$ & 1.5 & 2 & 0.60 & 3.0 & 1500 \\
\hline \multicolumn{7}{|c|}{ AMSU-B } \\
\hline$\overline{18}$ & $183.31 \pm 1.00$ & 0.5 & 2 & 1.06 & 1.1 & 2617 \\
\hline 19 & $183.31 \pm 3.00$ & 1.0 & 2 & 0.70 & 1.1 & 2617 \\
\hline 20 & $183.31 \pm 7.00$ & 2.0 & 2 & 0.60 & 1.1 & 2617 \\
\hline \multicolumn{7}{|c|}{ MHS } \\
\hline$\overline{1}$ & $183.31 \pm 1.00$ & 0.5 & 2 & 0.50 & 1.1 & 2617 \\
\hline 2 & $183.31 \pm 3.00$ & 1.0 & 2 & 0.41 & 1.1 & 2617 \\
\hline 3 & 190.31 & 2.0 & 1 & 0.55 & 1.1 & 2617 \\
\hline
\end{tabular}

\subsection{AMSU-B}

The Advanced Microwave Sounding Unit-B (AMSU-B) is a 5 channel microwave radiometer. The instrument is designed to receive and measure radiation from a number of different layers of the atmosphere in order to obtain global data on tropospheric humidity. It works in conjunction with the AMSU-A instruments to provide a 20 channel microwave radiometer.

Table 2. Time period for which UTH measurements are available from microwave instruments.

\begin{tabular}{c|c|c|c|c|c|c|c|c}
\hline \multicolumn{3}{|c}{ SSM/T2 } & \multicolumn{3}{c|}{ AMSU-B } & \multicolumn{3}{c}{ MHS } \\
\hline Satellite & Start Time & End Time & Satellite & Start Time & End Time & Satellite & Start Time & End Time \\
\hline F11 & $06 / 01 / 1994$ & $04 / 24 / 1995$ & N15 & $10 / 26 / 98$ & Present & N18 & $08 / 27 / 2003$ & Present \\
F12 & $10 / 13 / 1994$ & $01 / 08 / 2001$ & N16 & $01 / 24 / 01$ & Present & & & \\
F14 & $04 / 28 / 1997$ & Present & N17 & $06 / 25 / 02$ & Present & & & \\
F15 & $01 / 24 / 2000$ & Present & & & & & \\
\hline
\end{tabular}

The microwave characteristics of the atmosphere are provided in Figure 2. AMSU-B covers channels 16 through 20. The highest channels: 18, 19 and 20 span the strongly opaque water vapor absorption line at $183.31 \mathrm{GHz}$ and provide data on the atmospheric humidity at different levels. Channels 16 and 17 , at $89 \mathrm{GHz}$ and $150 \mathrm{GHz}$, respectively, enable deeper penetration through the atmosphere to the Earth's surface.

At each channel frequency, the antenna beamwidth is a constant 1.1 degrees (at the half power point). Ninety contiguous scene resolution cells are sampled in a continuous fashion, each scan covering \pm 49.5 degrees on each side of the subsatellite path. These scan patterns and geometric resolution translate to a $16.3 \mathrm{~km}$ diameter cell at nadir at a nominal altitude of $\sim 833 \mathrm{~km}$. The passbands for all five channels are shown in Figure 2 . The center frequencies for channels 18,19 , and 20 are $183.31 \pm 1.00 \mathrm{GHz}, 183.31 \pm 3.00 \mathrm{GHz}$, and $183.31 \pm 7.00 \mathrm{GHz}$, respectively. Further information regarding the AMSU-B channels can be found in Table 1. 


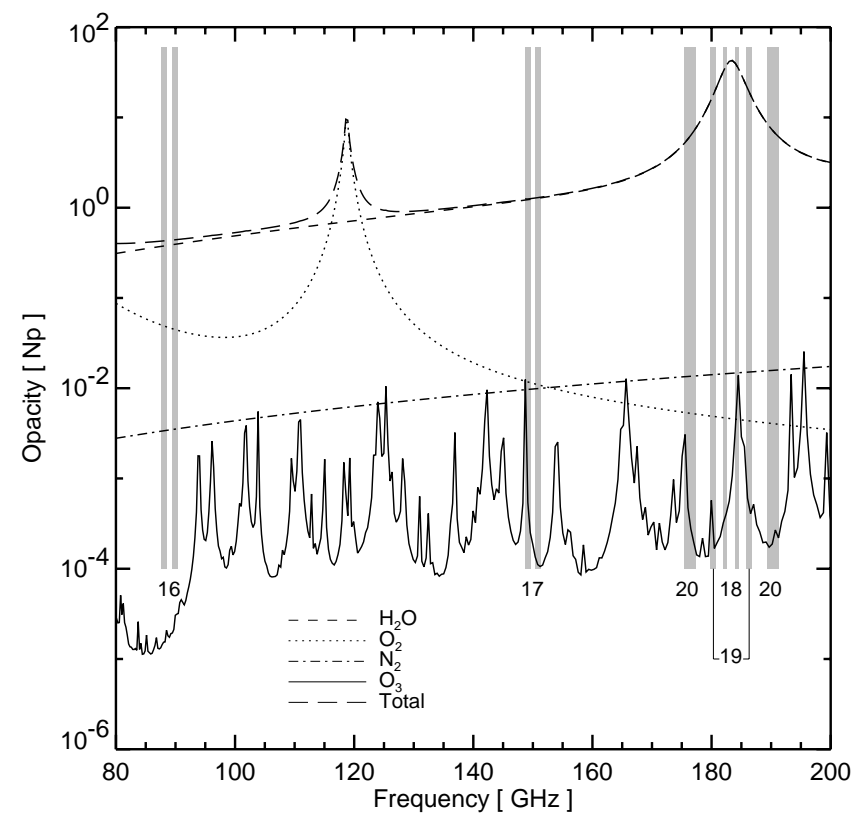

Figure 2. Atmospheric zenith opacity for the FASCOD midlatitude summer scenario for $\mathrm{H}_{2} \mathrm{O}$ (dashed), $\mathrm{O}_{2}$ (dotted), $\mathrm{N}_{2}$ (dash dotted), and $\mathrm{O}_{3}$ (solid). The long dashed line represents the total opacity. Shaded regions represent the passband positions of AMSU-B channels. The channel numbers are also printed near the passbands. Figure adapted from John and Buehler (2004). ${ }^{7}$

\subsection{MHS}

The Microwave Humidity Sounder (MHS) is a new instrument for the MetOp and NOAA series of satellites. It is also a five-channel microwave instrument to measure profiles of atmospheric humidity in complement to the instruments measuring temperatures on these satellites. It follows a similar specification to the AMSU-B instruments on the NOAA-K (15),-L (16),-M (17) satellites. EUMETSAT will fly the instrument on MetOp-1, -2 , and 3 and also provide copies of MHS for flight on NOAA-N (18) and -N'.

MHS is intended primarily for the measurement of atmospheric humidity, like the other two instruments. MHS has a circular field of view having a diameter of about $16 \mathrm{~km}$ at nadir. Ninety such fields of view are measured in each cross-track scan. The main difference between MHS and AMSU-B which is of interest to UTH study is that the channel at $183.31 \pm 7.00 \mathrm{GHz}$ on AMSU-B is replaced by a channel at $190.31 \mathrm{GHz}$ on MHS. A recent study by Kleespies and Watts $(2006)^{8}$ compared the brightness temperatures simulated for MHS and AMSU-B. They found that all channels around $183.31 \mathrm{GHz}$ show same brightness temperatures, except that the one at $183.31 \pm 7.00$ on AMSU-B measures slightly warmer radiances compared to its counterpart on MHS.

\section{RETRIEVAL OF UTH}

There is a simple relation, derived by Soden and Bretherton (1993), ${ }^{9}$ to estimate UTH from radiances, which was originally derived for infrared measurements:

$$
\ln (\mathrm{UTH})=a+b \times T_{\mathrm{B}},
$$

where $\ln (\mathrm{UTH})$ is the natural logarithm of Jacobian weighted mean of the fractional relative humidity in the upper troposphere, $T_{\mathrm{B}}$ is the radiance expressed in brightness temperature, and $a$ and $b$ are constants. The constants are different for microwave and infrared cases or if one uses different definitions of the Jacobian. ${ }^{10}$ It is shown in Buehler and John $(2005)^{10}$ that this method works well for AMSU-B Channel 18 brightness temperatures. The absolute error in UTH obtained by this method is $2 \% \mathrm{RH}$ at low UTH values and $6 \% \mathrm{RH}$ 


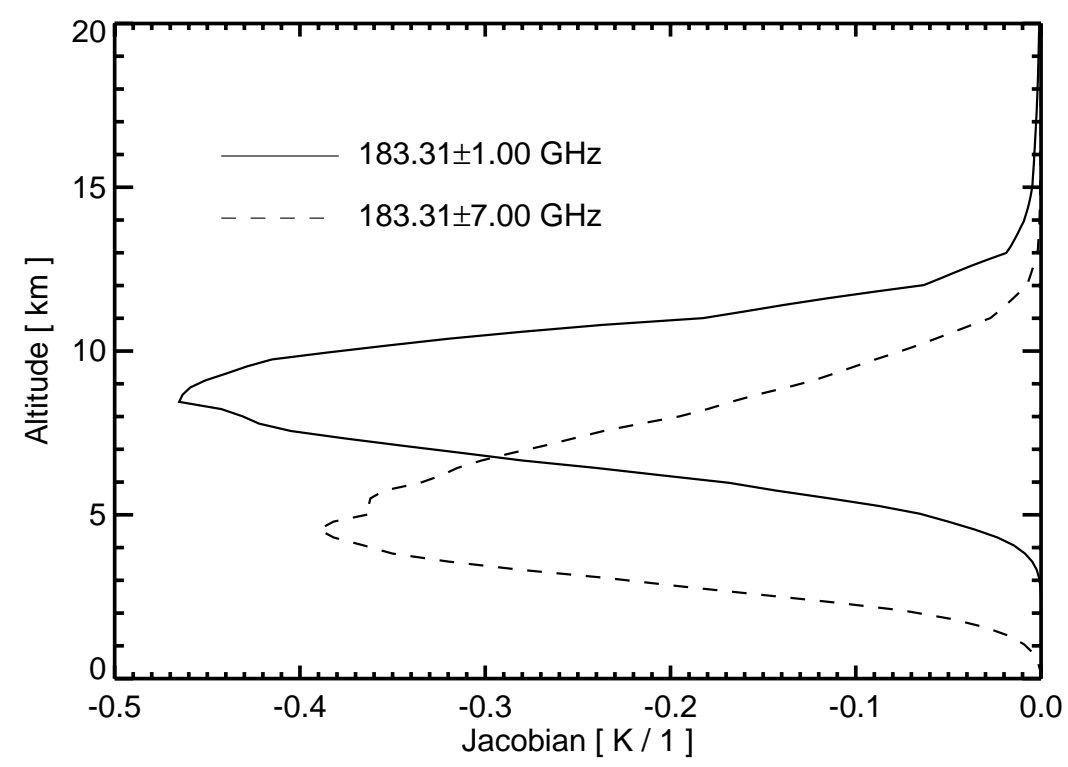

Figure 3. Water vapor Jacobians (defined as change in brightness temperature for change in water vapor) for $183.31 \pm 1.00 \mathrm{GHz}$ and $183.31 \pm 7.00 \mathrm{GHz}$ channels for a midlatitude summer atmosphere.

at high UTH values. The ECMWF 60 level sampled data set ${ }^{11}$ was used to derive the coefficients $a$ and $b$ in Equation (1). The coefficients were derived for all AMSU-B viewing angles (45 angles from $0.55^{\circ}$ to $48.95^{\circ}$ from nadir in $1.1^{\circ}$ steps) so that the brightness temperatures do not need to be limb corrected. The relation basically provides a tool to transform the brightness temperatures to an intuitive quantity, relative humidity, rather than a retrieval in the normal sense.

\subsection{Cloud Issues}

Although microwave measurements are transparent to most of the clouds, they are contaminated in the presence of clouds with large ice particles and precipitation. Ice or rain particles scatters the radiation away from the line of the sight of the instrument and thus reduce the amount of radiation that should reach the instrument. This would results in a depression in brightness temperature measured. In Equation (1) $a$ is positive and $b$ is negative, therefore a decrease in brightness temperature would increase UTH. A very large depression in brightness temperature thus would lead to unrealistically high UTH values.

Greenwald and Christopher $(2002)^{6}$ investigated the impact of clouds on $T_{\mathrm{B}}^{ \pm 1}$. They used Advanced Very High Resolution Radiometer (AVHRR) data in addition to microwave data to estimate a clear-sky background of $T_{\mathrm{B}}^{ \pm 1}$ in order to estimate the cloud contamination.

Recently, Buehler et al. $(2006)^{12}$ put forward a method to filter cloudy $T_{\mathrm{B}}^{ \pm 1}$ pixels using microwave measurements alone. As shown in Figure 3 measurements at $183.31 \pm 7.00 \mathrm{GHz}\left(T_{\mathrm{B}}^{ \pm 7}\right)$ are sensitive to radiance emitted from the lower layers of the troposphere compared to the measurements at $183.31 \pm 1.00 \mathrm{GHz}$, therefore we expect $T_{\mathrm{B}}^{ \pm 7}$ to be warmer than $T_{\mathrm{B}}^{ \pm 1}\left(\Delta T_{\mathrm{B}}>0\right)$ under clear-sky conditions. This will be reversed, i.e., $\Delta T_{\mathrm{B}}<0$, in the presence of clouds due to scattering effects.

One can also estimate a minimum value of $T_{\mathrm{B}}^{ \pm 1}$ for each viewing angle for clear-sky conditions. These are estimated from clear-sky simulations and are shown in Figure 4. The threshold values follow limb darkening of the radiances as the instruments scans away from the nadir. ${ }^{13}$

Buehler et al. $(2006)^{12}$ combined these two criteria to detect cloud contaminated $T_{\mathrm{B}}^{ \pm 1}$ measurements. They demonstrated the robustness of the method using a case study, please see Buehler et al. $(2006)^{12}$ for further details. They also show cloud effect on UTH by calculating the difference of total sky (clear + cloudy pixels) UTH and clear sky UTH from the real AMSU-B data. Figure 5 shows this for a winter season. 


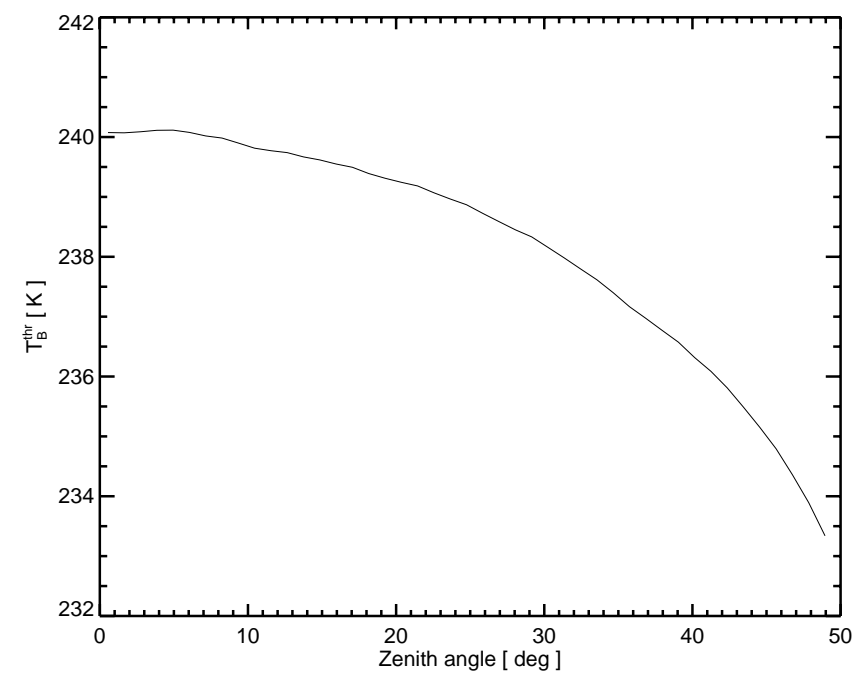

Figure 4. Threshold values of clear-sky $T_{\mathrm{B}}^{ \pm 1}$ for each viewing angle of the instrument. There values were derived using the ECMWF 60 level sampled data set. ${ }^{11}$

Total - Clear Sky, NOAA-16, winter, 2001

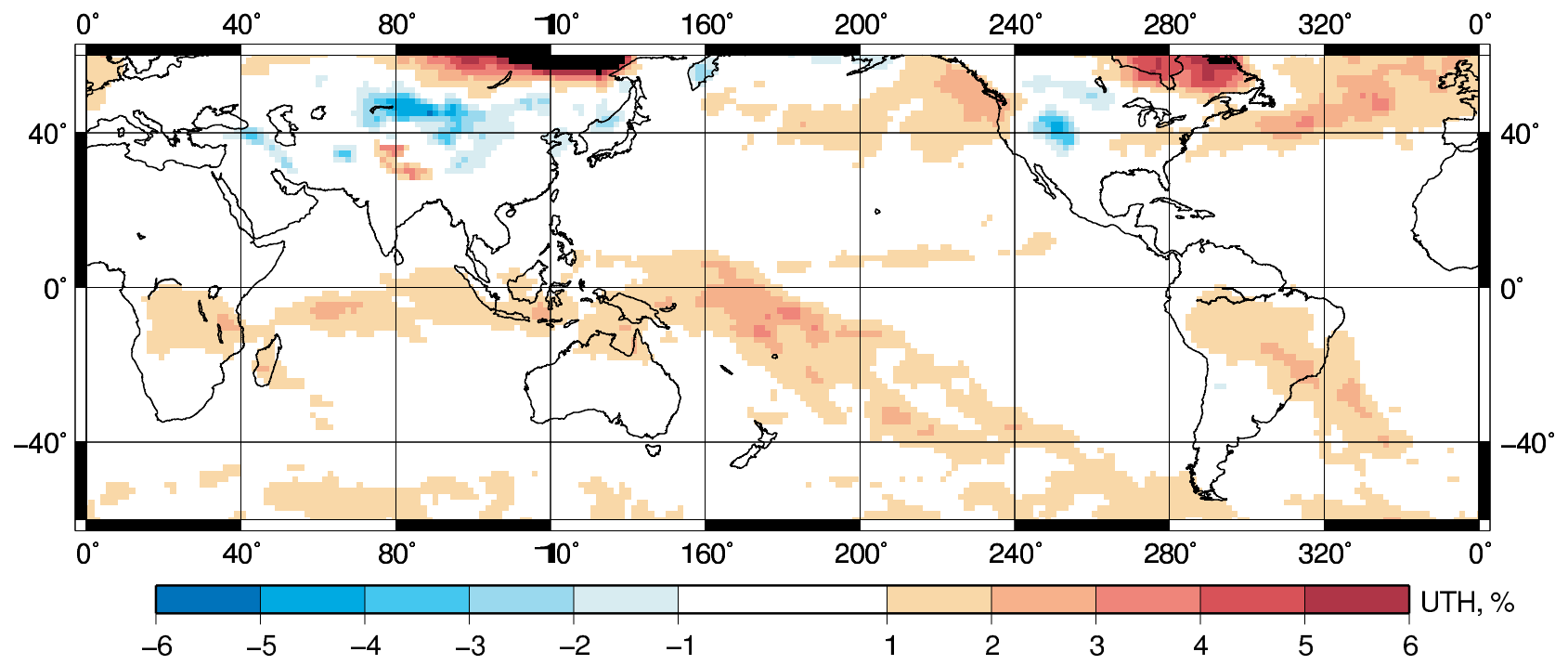

Figure 5. Cloud effect on AMSU-B data. Difference between UTH derived from all available data and UTH derived from data which passed cloud filter described in Section sec:cloud. The data used are from NOAA 16, from December 2001 to February 2002. Maximum, minimum, and mean of the $\Delta \mathrm{UTH}$ on the plot are $10.7,-7.3$ and $0.6 \pm 1.0 \% \mathrm{RH}$, respectively. Figure from Buehler et al. $(2006)^{12}$ 

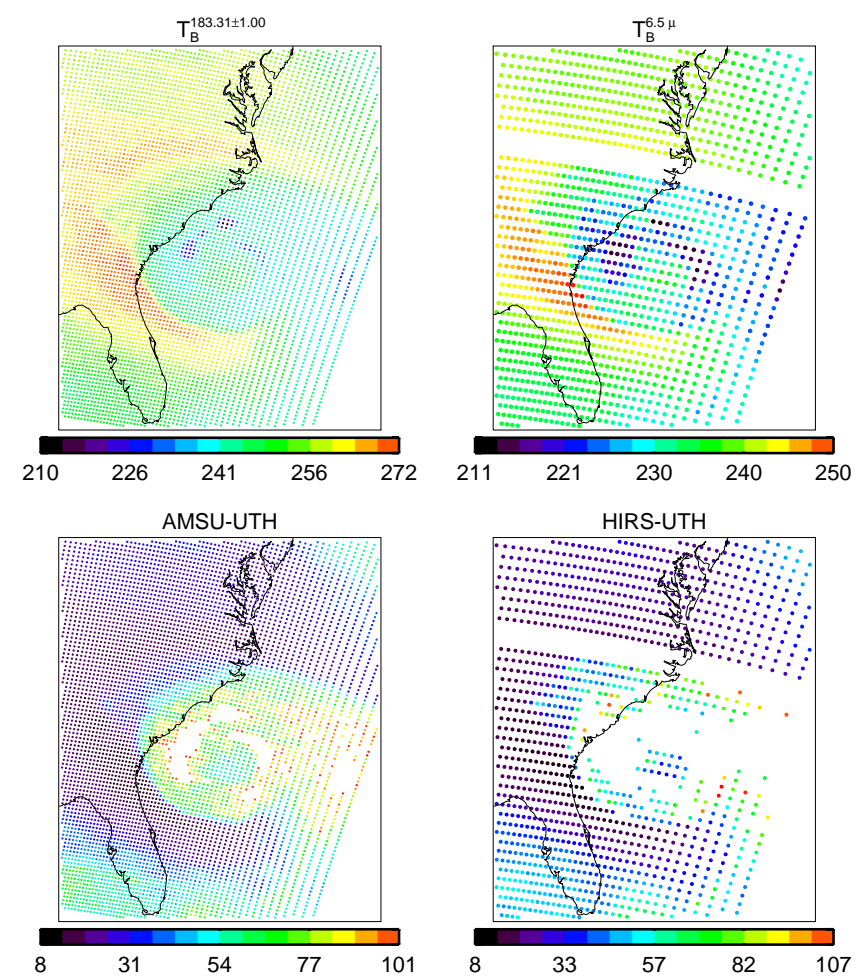

Figure 6. Advantage of microwave measurements over infrared measurements with respect to cloud contamination. Upper left panel shows $T_{\mathrm{B}}^{ \pm 1}$, upper right panel shows $T_{\mathrm{B}}^{6.5 \mu}$, lower left panel shows UTH with respect to ice derived from $T_{\mathrm{B}}^{ \pm 1}$, and lower right panel shows UTH with respect to ice derived from $T_{\mathrm{B}}^{6.5 \mu}$. For microwave measurements, the cloud filter discussed in Section 3.1 is used and for infrared measurements the cloud filter is $T_{\mathrm{B}}^{11 \mu}-T_{\mathrm{B}}^{6.5 \mu}>30 \mathrm{~K}$. The scene presented is for the hurricane Ophelia on September 12, 2005. $T_{\mathrm{B}} \mathrm{S}$ are in Kelvin and UTH are in \% RH.

It is clear from Figure 5 that active convective regions do have a positive difference. That is, at those regions total sky UTH is larger than clear sky UTH. It is very well known that there is a high positive correlation between ice water and water vapor in the upper troposphere due to their common origin, i.e., convective transport. ${ }^{14}$ Therefore removing cloudy pixels would eventually remove measurements with high humidity values and thus introduce a dry bias in the data set derived from cloud cleared measurements. This is generally called as "clearsky bias". ${ }^{5}$ The positive areas in Figure 5 are an over estimate of the clear-sky bias because the original UTH value will be in between the total-sky UTH and clear-sky UTH.

Figure 6 illustrates the advantage of microwave measurements over infrared using a scene over a category 1 hurricane (Ophelia, September 12, 2005). The aforesaid cloud filter is used for microwave measurements. For infrared measurements, the cloudy pixels are removed using $T_{\mathrm{B}}^{11 \mu}-T_{\mathrm{B}}^{6.5 \mu}>30 \mathrm{~K}$. It is clear from the figure that in case of microwave, only pixels over precipitation bands are removed where as in case of infrared, pixels over most of the hurricane region are removed (see Figure 7 for precipitation bands). Thus, microwave measurements UTH can be used to study the evolution of upper tropospheric water vapor associated with hurricane formation.

\subsection{Surface Influence}

Measurements at $183.31 \pm 1.00 \mathrm{GHz}$ can be contaminated by surface when the atmosphere is very dry. In that case measurements at $183.31 \pm 7.00 \mathrm{GHz}$ are obviously contaminated by surface because the atmospheric opacity (absorption) is smaller for the latter (see Figure 2). If we assume the surface emissivity to be the same for both channels, $T_{\mathrm{B}}^{ \pm 1}$ will be warmer than $T_{\mathrm{B}}^{ \pm 7}$ because the contribution of atmospheric emission will be more for the former as the frequencies are closer to the line center. Therefore, the cloud filter described in Section 3.1 can also be used to remove $T_{\mathrm{B}}^{ \pm 1}$ which are contaminated by surface. 


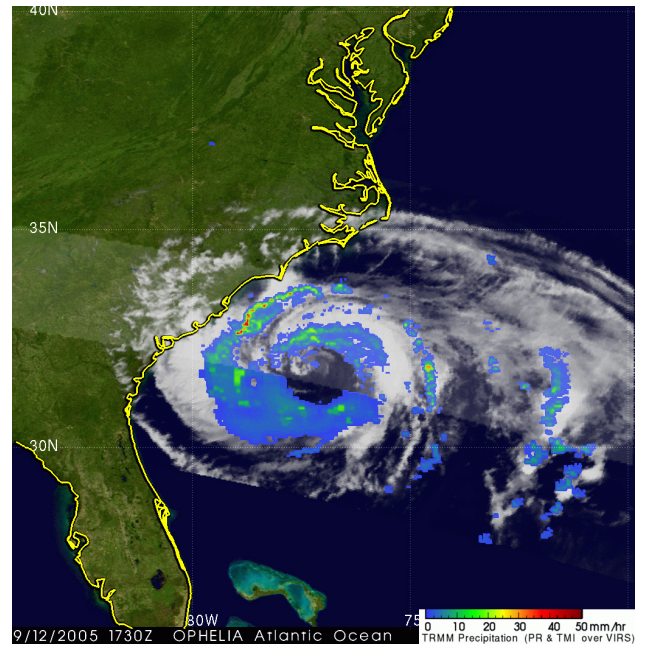

Figure 7. TRMM precipitation rate and IR image at 17:30 UTC on 12 September 2005 of hurricane Ophelia. Rain rates in the inner swath are from the TRMM Precipitation Radar (PR), and rates in the outer swath are from the TRMM Microwave Imager (TMI). The rainfall pattern is overlaid on infrared (IR) data from the TRMM Visible Infrared Scanner (VIRS). Figure taken from NASA's hurricane web page.
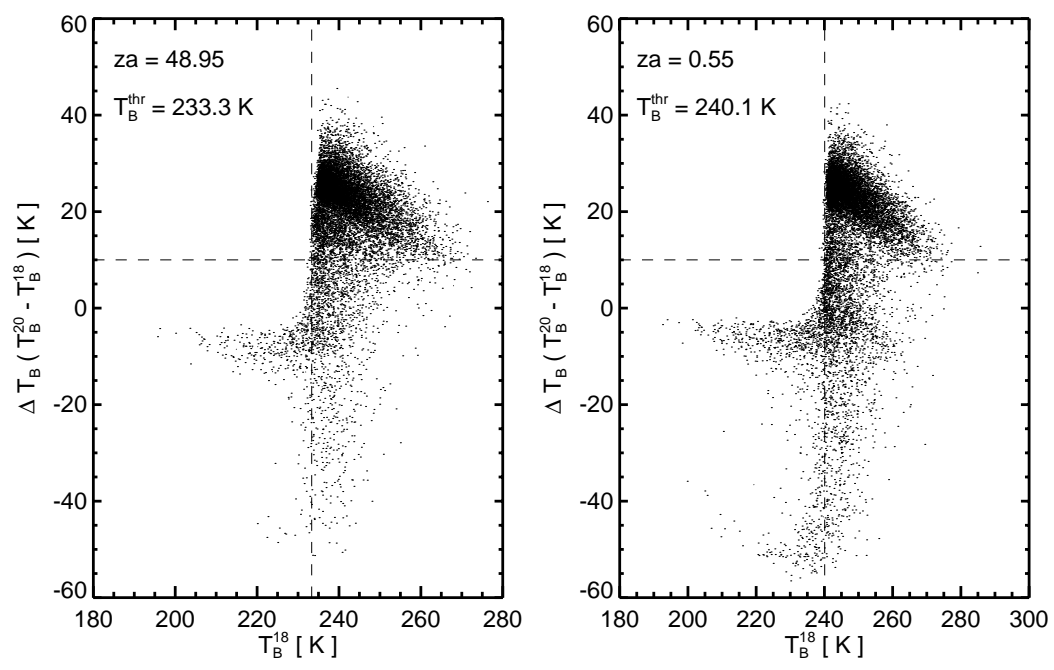

Figure 8. $\Delta T_{\mathrm{B}}\left(T_{\mathrm{B}}^{ \pm 7}-T_{\mathrm{B}}^{ \pm 1}\right)$ as a function of $T_{\mathrm{B}}^{ \pm 1}$. These clear-sky brightness temperatures are simulated using the ECMWF 60 level sampled data set. ${ }^{11}$ Right panel for nadir viewing geometry and left panel for maximum off-nadir viewing geometry. 


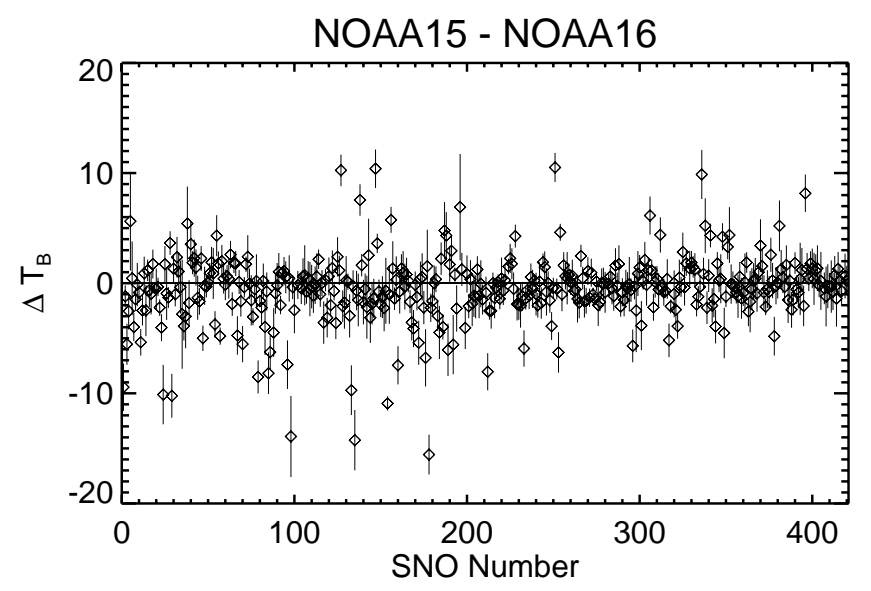

Figure 9. Difference between NOAA-15 and NOAA-16 AMSU-B Channel 18 brightness temperatures during SNO.

Figure 8 shows $\Delta T_{\mathrm{B}}$ as a function of $T_{\mathrm{B}}^{ \pm 1}$. These clear-sky brightness temperatures are simulated using the ECMWF 60 level sampled data set. ${ }^{11}$ It is evident that $\Delta T_{\mathrm{B}}$ can be negative almost at the entire range of $T_{\mathrm{B}}^{ \pm 1}$. Therefore UTH derived from surface contaminated $T_{\mathrm{B}}^{ \pm 1}$ can be higher or lower than the original UTH based on the surface conditions like surface emissivity and surface temperature.

In summary, the filter removes cloudy as well as surface contaminated $T_{\mathrm{B}}^{ \pm 1}$ successfully. In cloudy cases it removes humid measurements thus introduces as dry bias (most of the red areas in Figure 5 due to removal of humid pixels). Surface contamination always represent dry cases, therefore one would expect a wet bias at those regions (blue areas in Figure 5 due to removal of dry pixels). But there can be two cases: (1) radiometrically cold surface - since the $T_{\mathrm{B}}^{ \pm 1}$ are cold, one gets an apparent humid UTH, thus a dry bias (red areas). An example for this is Himalayas in Figure 5. This is in general true for elevated, ice covered regions such as Antarctic or Greenland. (2) radiometrically warm surface: desert or snow covered areas with high emissivity, one gets warmer $T_{\mathrm{B}}^{ \pm 1}$, thus a drier UTH than normal. When those dry values are removed one gets a wet bias (blue areas) in the climatology. Thus, one can have either dry or wet bias in UTH climatologies based on these conditions.

\section{INTER-CALIBRATION}

The first step towards homogenized, long-term data set from satellite measurements is the inter-calibration of the instruments on different satellites. Recently, Cao et al. $2004^{15}$ demonstrated a method to inter-calibrate instruments on polar orbiting satellites using Simultaneous Nadir Overpasses (SNO) of the satellites. Figure 9 shows preliminary results of inter-calibration of AMSU-B instruments using this method. It shows the difference in brightness temperature (mean and standard deviation of pixels in a target box) for NOAA-15 and NOAA-16. At this stage of the work, there is no evident systematic bias for Channel 18 of AMSU-B for NOAA-15 and NOAA-16. Further analysis is underway to inter-calibrate all the instruments using this method.

\section{SUMMARY}

Some ideas and issues related to the development of a long-term upper tropospheric humidity (UTH) data set using satellite based microwave measurements are presented. Polar orbiting satellites have been measuring UTH since 1994. The three main microwave instruments which can measure UTH from Space are: Special Sensor Microwave/Temperature-2 (SSM/T2), Advanced Microwave Sounding Unit-B (AMSU-B), and Microwave Humidity Sounder (MHS). These instruments have channels at $183.31 \pm 1.00 \mathrm{GHz}$ which are sensitive to UTH. A simple methodology to estimate UTH from $183.31 \pm 1.00 \mathrm{GHz}$ radiance is briefly discussed. Also, the cloud issues and surface issues are discussed. Moreover, the advantage of microwave measurements of UTH over infrared measurements is demonstrated. Preliminary results on the inter-calibration of these instruments are also presented. 


\section{ACKNOWLEDGMENTS}

We acknowledge J. Miao for his work on the 2D cloud filter. We thank the UK MetOffice for providing us with the mesoscale model outputs. Also, we thank the ARTS radiative transfer community. Thanks to Nathalie Courcoux for providing us with RTTOV simulations. Thanks to Lisa Neclos from the Comprehensive Large Array-data Stewardship System (CLASS) of the US National Oceanic and Atmospheric Administration (NOAA) for AMSU data. Thanks again to Met Office (UK) for providing the AAPP software. This study was partly funded by the German Federal Ministry of Education and Research (BMBF), within the AFO2000 project UTH-MOS, grant 07ATC04. It is a contribution to COST Action 723 'Data Exploitation and Modeling for the Upper Troposphere and Lower Stratosphere'.

\section{REFERENCES}

1. S. Bony, R. Colman, V. M. Kattsov, R. P. Allan, C. S. Bretherton, J. L. Dufresne, A. Hall, S. Hallegatte, M. M. Holland, W. Ingram, D. A. Randall, B. J. Soden, G. Tselioudis, and M. J. Webb, "How well do we understand and evaluate climate change feedback processes?," J. Climate 19(15), pp. 3445-3482, 2006.

2. B. J. Soden and I. M. Held, "An assessment of climate feedbacks in coupled atmosphere-ocean models," $J$. Climate 19(14), pp. 3354-3360, 2006.

3. P. M. F. Forster and M. Collins, "Quantifying the water vapor feedback associated with post-Pinatubo global cooling," Clim. Dyn. 23, pp. 207-214, doi:10.1007/s00382-004-0431-z, 2004.

4. L. Garand, D. S. Turner, M. Larocque, J.Bates, S. Boukabara, P. Brunel, F. Chevallier, G. Deblonde, R. Engelen, M. Hollingshead, D. Jackson, G. Jedlovec, J. Joiner, T. Kleespies, D. S. McKague, L. McMillin, J.-L. Moncet, J. R. Pardo, P. J. Rayer, E. Salathe, R. Saunders, N. A. Scott, P. V. Delst, and H. Woolf, "Radiance and Jacobian intercomparison of radiative transfer models applied to HIRS and AMSU channels," J. Geophys. Res. 106(D20), pp. 24,017-24,031, 2001.

5. J. R. Lanzante and G. E. Gahrs, "The "clear-sky bias" of TOVS upper-tropospheric humidity," J. Clim. 13, pp. 4034-4041, November 2000.

6. T. J. Greenwald and S. A. Christopher, "Effect of cold clouds on satellite measurements near $183 \mathrm{GHz}$," J. Geophys. Res. 107(D13), p. 4170, 2002.

7. V. O. John and S. A. Buehler, "The impact of ozone lines on AMSU-B radiances," Geophys. Res. Lett. 31, L21108, doi:10.1029/2004GL021214, 2004.

8. T. J. Kleespies and P. Watts, "Comparison of simulated radiances, Jacobians and retrieval performance for the Microwave Humidity Sounder and the Advanced Microwave Sounding unit," Q. J. R. Meteorol. Soc. , 2006. in press.

9. B. J. Soden and F. P. Bretherton, "Upper Tropospheric Relative Humidity From the GOES $6.7 \mu$ m Channel: Method and climatology for July 1987," J. Geophys. Res. 98, pp. 16669-16688, September 1993.

10. S. A. Buehler and V. O. John, "A simple method to relate microwave radiances to upper tropospheric humidity," J. Geophys. Res. 110, D02110, doi:10.1029/2004JD005111, 2005.

11. F. Chevallier, "Sampled databases of 60-level atmospheric profiles from the ECMWF analysis," tech. rep., ECMWF, 2001. EUMETSAT SAF program research report no. 4.

12. S. A. Buehler, M. Kuvatov, T. R. Sreerekha, and V. O. John, "A cloud filtering method for microwave upper trpospheric humidity measurements," Atmos. Chem. Phys., submitted 2006.

13. S. A. Buehler, M. Kuvatov, V. O. John, U. Leiterer, and H. Dier, "Comparison of microwave satellite humidity data and radiosonde profiles: A case study," J. Geophys. Res. 109, D13103, doi:10.1029/2004JD004605, 2004.

14. V. O. John and B. J. Soden, "Does convectively-detrained cloud ice enhance water vapor feedback?," Geophys. Res. Lett. 33, L20701, doi:10.1029/2006GL027260, 2006.

15. C. Cao, M. Weinreb, and H. Xu, "Predicting simultaneous nadir overpasses among polar-orbiting meteorological satellites for the intersatellite calibration of radiometers," J. Atmos. Ocean Technol. 21, pp. 537-542, 2004 . 